\title{
Maxillary Dentigerous Cyst Associated With Supernumerary Tooth
}

\author{
Prashant Nanwani ${ }^{1}$
}

\author{
Introduction: \\ Dentigerous cysts are caused by a developmental abnormality derived from the reduced enamel epithelium of the tooth-forming \\ organ. Dentigerous cyst rarely involve impacted supernumerary tooth in anterior maxilla while commonly involve third molar \\ tooth. \\ Case Report: \\ A case of dentigerous cyst in association with supernumerary tooth in a 15-year-old male patient is reported causing right nasal \\ cavity obstruction. The present case report describes the management of a dentigerous cyst by surgical enucleation. \\ Kevwords: \\ Dentigerous Cyst; Tooth, Supernumerary; Maxilla; Nasal Obstruction
}

\section{$\underline{\text { ABSTRACT }}$}

$\mathrm{D}$ entigerous cysts are one of the most prevalent types of odontogenic cysts, mostly associated with an embedded or unerupted tooth. Dentigerous cyst may involve supernumerary teeth, impacted teeth, odontomas and rarely decidual teeth. ${ }^{1}$ These are usually associated with mandibular third molar, maxillary permanent canine, mandibular premolars, maxillary third molars in decreasing order. These rarely involves central incisors, supernumerary teeth eg. mesiodens and distomolars. ${ }^{2}$

Stafne et al reported that the incidence of dentigerous cysts associated with supernumerary teeth is only $5.5 \%$ most developing around a mesiodens in the anterior maxilla. 'Mesiodens' are the most common supernumerary teeth situated between the maxillary central incisors. $0.15 \%$ to $3.8 \%$ incidence of supernumerary tooth is found in population with $90 \%$ to $98 \%$ in maxilla, preferably in premaxilla. ${ }^{4,5}$ Dentigerous cysts usually found at first to fourth decade of life with slight male predilection. ${ }^{2}$

The reduced epithelium forms bed for the origin of

1 - Department of ENT, Pt.J.N.M.Medical

College,Raipur,Chhattisgarh

\section{Corresponding author:}

Dr Prashant Nanwani

email: prashantnanwani@yahoo.in dentigerous cyst because of cystic degeneration of remaining enamel organ which leads to accumulation of fluid by degeneration of epithelial cells. ${ }^{6}$ These are usually incidental findings in routine $\mathrm{X}$-rays.

There are various treatment options for dentigerous cyst, ranging from marsupialisation to complete enucleation, including the exodontia of unerupted tooth. ${ }^{7}$

We are presenting a dentigerous cyst in upper maxillary region in a 15 -year-old male, associated with a supernumerary tooth; causing right sided nasal obstruction. We shall review the relevant literature.

\section{Case Report}

A 15 years old boy reported to the department of ENT \& Head \& Neck Surgery, with chief complaints of swelling over right cheek since three and half months, right sided nasal obstruction since 1 month and pain over swelling since 15 days.(Fig. 1) The boy had history of seizure disorder and was on regular treatment for the same; since 5 months (Tab. Phenytoin $50 \mathrm{mg}$ tds).

Intra-oral examination revealed firm, non-tender swelling over maxillary right gingivolabial sulcus spanning from lateral incisor second premolar.(Fig. 2) The overlying palatal and labial mucosa were normal.

On anterior rhinoscopy, there was bulge over lateral 


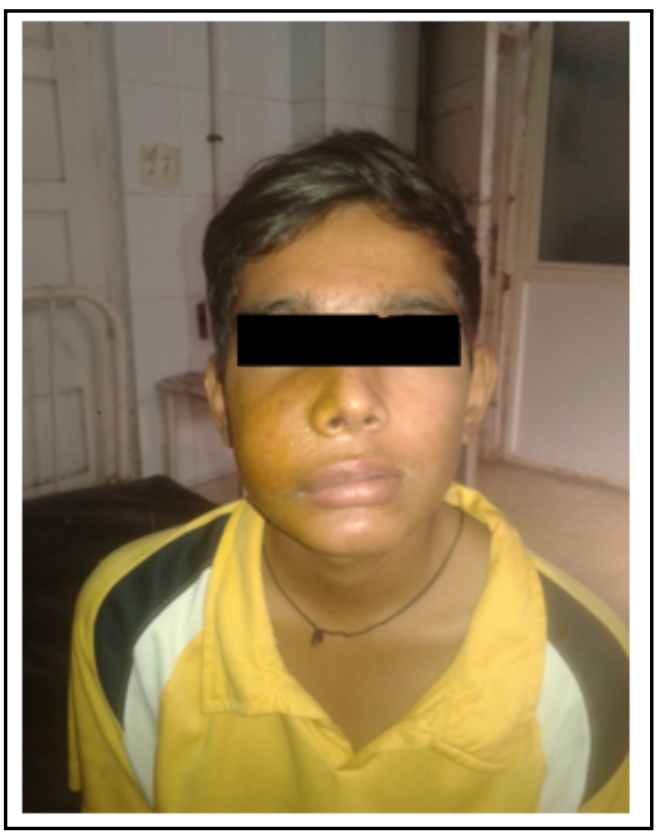

Fig.1. Swelling over right cheek

wall of right nasal cavity due to swelling over right cheek which was causing right sided nasal obstruction. (Fig. 3)

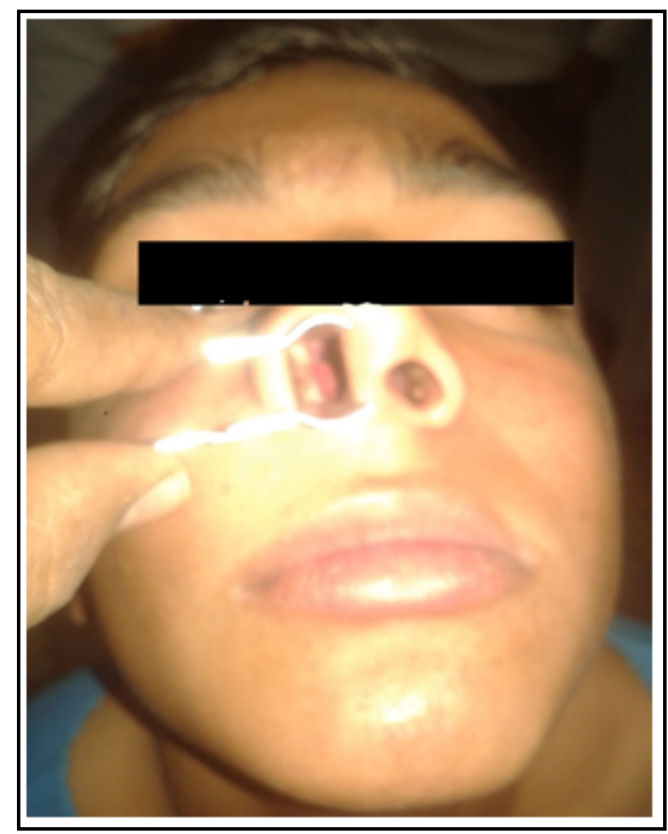

Fig.3. Showing bulge in right nasal cavity

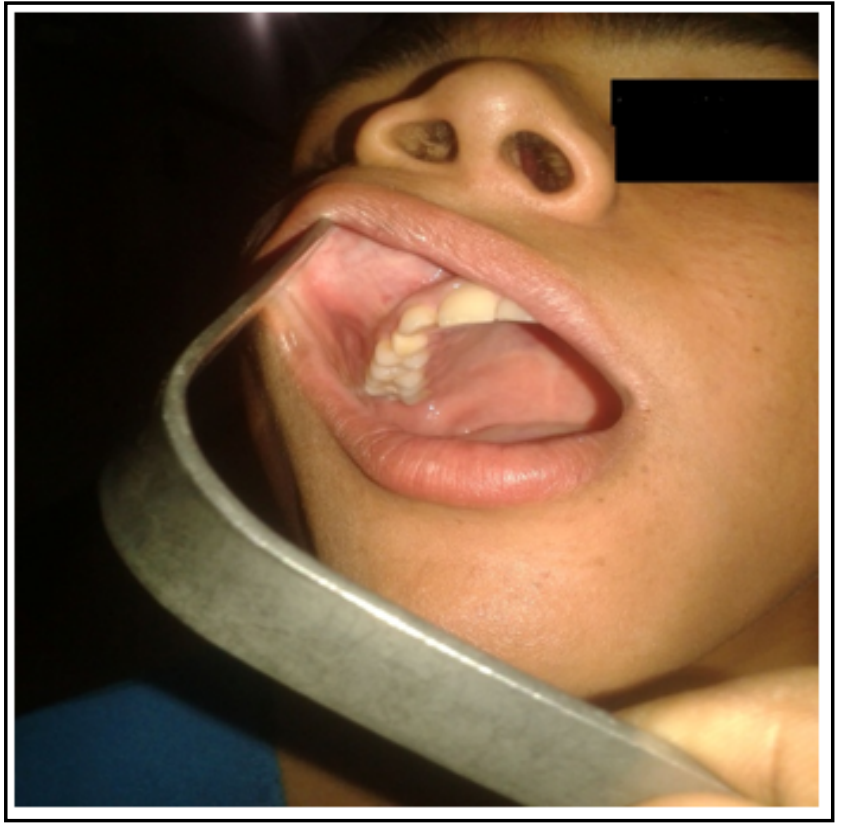

Fig.2. Intra-oral examination showing swelling

USG of right cheek swelling showed a well-defined anechoic cystic lesion of size $2.8 \times 2.9 \mathrm{~cm}$ seen in the right maxillary region with echogenic component (most probably a tooth), findings suggestive of dentigerous cyst.

CT Scan PNS showed a well-defined lesion of size $2.5 \times 2.8 \mathrm{~cm}$ showing fluid attenuation with impacted crown of unerupted tooth seen in the anterior medial aspect of right maxillary sinus abutting right lateral wall of nose and inferior turbinate and causing partial obliteration of right nasal cavity. Features are suggestive of dentigerous cyst in right maxilla.(Fig. 4)

HPE-Gross- showed multiple irregular grayish brown soft tissue measuring $1 \times 1 \times 0.5 \mathrm{~cm}$ along with tooth. Microscopic-showed cyst lined with stratified squamous epithelium with foci of calcification. Findings consistent with dentigerous cyst.

\section{Discussion}

Supernumerary teeth noted in less than $1 \%$ of population may cause alteration in neighbouring teeth or disorder in dental eruption. Developmental abnormalities and hyperactivity of the dental plate is the most accepted 


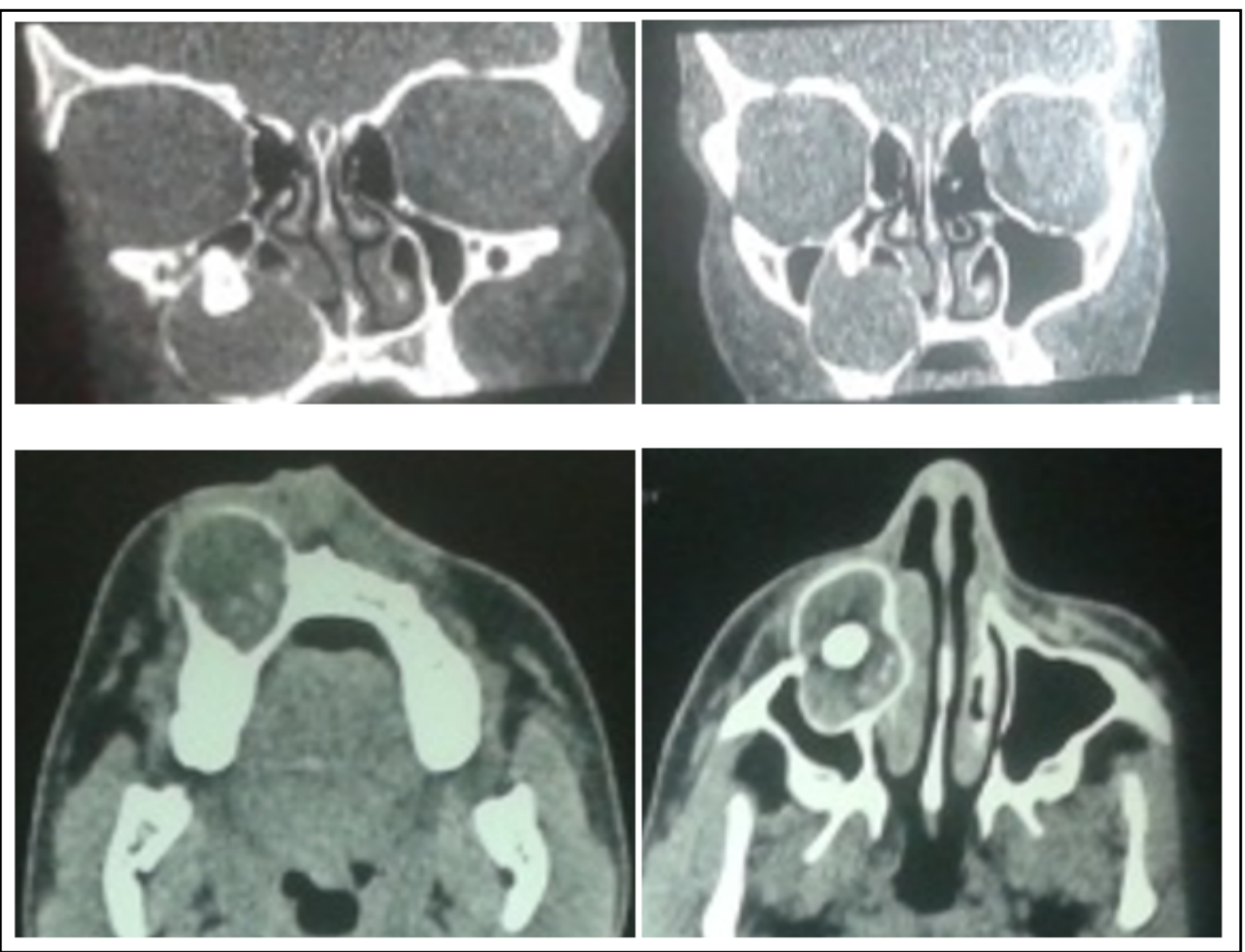

Fig.4. CT scan PNS showing dentigerous cyst with impacted tooth

theory for their formation. ${ }^{8}$

Dentigerous means 'tooth bearing'. Dentigerous cyst is the second most common odontogenic cyst of jaw after radicular cyst. ${ }^{6,9}$ Association between dentigerous cyst and supernumerary teeth is an unusual pathology. ${ }^{7}$, $8,9,10,11$ Jiang et al's ${ }^{10}$ literature review spanning from 1988 to 2011 discloses the publication of 16 cases of dentigerous cyst associated to supernumerary teeth in the premaxilla.

Zhang et al. ${ }^{7}$ in his study found $1 \%$ dentigerous cyst were related to impacted supernumerary tooth, $98 \%$ were related to molars.

Stafne $^{3}$ found that $5.5 \%$ of supernumerary teeth developed dentigerous cysts. Hurlen and Humerfelt ${ }^{12}$ found a correlation of $7 \%$ and Asaumi et al. ${ }^{13}$ stated that dentigerous cysts associated to supernumerary teeth account for $11 \%$ of the cases.

Theories of Dentigerous cyst formation:

Intra-follicular theory: Fluid accumulates between inner and outer enamel epithelium and resultant cyst formation occurs after crown formation.

Enamel hypoplasia theory: It states that due to degenerative process initially in stellate reticulum stage of tooth development. Enamel hypoplasia is also associated with it.

Main's theory: Accumulation of fluid between reduced enamel epithelium and enamel leads to formation of dentigerous cyst.

Guidelines for diagnosis of dentigerous cyst (Daley and Winsock): ${ }^{14}$

- Greater than $4 \mathrm{~mm}$ pericoronal radiolucency in 
radiology

-Non-keratinising stratified squamous epithelium lining a fibrous tissue

-Cystic space between enamel and overlying tissue demonstrable surgically

Bone cortical affection and neighbouring teeth assessment can be done by maxillary CT scan. ${ }^{11}$ The final diagnosis is made according to histological analysis of lesion, where non-keratinised stratified epithelium is found.

Treatment of dentigerous cyst is decided depending on size, location and the probability of disfigurement. If a cyst is very large and in vicinity of vital structure, marsupialisation is done. The cyst should be enucleated along with extraction of involved tooth if cyst is associated with supernumerary or wisdom tooth. If dentigerous cyst left untreated there may be some complications like bone deformity, permanent bone deformation, loss of permanent teeth, squamous cell carcinoma, mural ameloblastoma and mucoepidermoid carcinoma. ${ }^{15}$ In our case, enucleation of cyst was done along with removal of impacted supernumerary tooth.

\section{Conclusion}

Occurrence of the dual pathology like dentigerous cyst of maxilla and association with supernumerary tooth is quite rare. A CT would be necessary to assess the neighbouring teeth's affectation, quantity of bone involved and extension of the lesion to the surroundings such as nasal cavity, orbit etc. The histopathologic study of the surgically removed piece will determine the confirmed diagnosis.

\section{References}

1. Agrawal M, Raghavendra PD, Singh B, Agrawal N. Multiple teeth in a single dentigerous cyst follicle: A perplexity. Ann MaxillofacSurg. 2011; 1:187-9
2. Lustmann J, Bodner L. Dentigerous cysts associated with supernumerary teeth. Int J Oral Maxillofac Surg. 1988; 17:1002

3. Stafne EC. Supernumerary upper central incisor. Dental Cosmos 1931; 73: 976-98

4. Primosch RE. Anterior supernumerary teeth-assessment and surgical intervention in children. Pediatr Dent. 1981; 3(2):20415

5. Nazif MM, Ruffalo RC, Zullo T. Impacted supernumerary teeth: A survey of 50 cases. J Am Dent Assoc. 1983;106(2):201-4

6. Vega Llauradó A, Ayuso Montero R, TeixidorOlmo I, Salas Enric J, MaríRoig A, LópezLópezJ. pcionesterapéuticasenquistesodontogénicos. Revision. Avancesen Odontoestomatologia 2013; 29:81-93

7. Zhang LL, Yang R, Zhang L, Li W, MacDonald-Jankowski D, Poh CF. Dentigerous cyst: a retrospective clinicopathological analysis of 2082 dentigerous cysts in British Columbia, Canada. Int J Oral Maxillofac Surg. 2010; 39:878-82

8. Shun Y. Dentigerous cyst associated with an impacted anterior maxillary supernumerary tooth. Journal of Dentistry for Children (Chicago) 2008; 75:104-7

9. Manor E, Kachko L, Puterman MB, Szabo G, Bodner L. Cystic lesions of the jaws. A Clinicopathological study of 322 cases and review of the literature. International Journal of Medical Sciences 2012; 9:20-6

10. Jiang $\mathrm{Q}, \mathrm{Xu}$ GZ, Yang C, Yu CQ, He DM, Zhang ZY. Dentigerous cysts associated with impacted supernumerary teeth in the anterior maxilla. Experimental and Therapeutic Medicine 2011; 2:805-9

11. Kim KS, Mun SK. Extensive dentigerous cyst associated with a mesiodens: CT findings. Ear, Nose and Throat Journal 2013; 92:E6-E8

12. Hurlen B, Humerfelt D. Characteristics of premaxillaryhyperdontia. A radiographic study. Acta Odontologica Scandinavica 1985; 43:75-81

13. Asaumi JI, Shibata Y, Yanagi Y. Radiographic examination of mesiodens and their associated complications. Dento Maxillo Facial Radiology 2004; 33:125-7

14. Daley TD, Wysocki GP. The small dentigerous cyst: A diagnostic dilemma. Oral Surgery, Oral Medicine, Oral Pathology. Oral Radiology and Endodontology 1995; 79:77-81

15. Mishra S, Passi D, Srivastava D, Chandra L. Maxillary Dentigerous Cyst Associated with Impacted Mesiodens: A Rarest Combination of Two Ectopic Pathological Entitity: Case Report and Literature Review. Ann Med Health Sci Res. 2017; 7: 57-60. 